\title{
IMPLEMENTASI SCIENTIFIC APPROACH PADA OUTDOOR LEARNING UNTUK MENINGKATKAN MOTIVASI BELAJAR MAHASISWA PENDIDIKAN IPA
}

\author{
Tias Ernawati \\ Prodi Pendidikan IPA FKIP UST Yogyakarta \\ E-mail: tias.ernawati@ustjogja.ac.id
}

\begin{abstract}
Abstrak. Penelitian ini bertujuan untuk mengetahui bahwa implementasi scientific approach pada outdoor learning dalam mata kuliah Ilmu Lingkungan dapat meningkatkan motivasi belajar mahasiswa Program Studi Pendidikan IPA Semester Genap T.A. 2014/2015. Penelitian ini adalah penelitian tindakan kelas yang terdiri dari dua siklus. Setiap siklus terdiri dari perencanaan tindakan, pelaksanaan dan observasi, serta refleksi. Pelaksanaan tindakan dilakukan dengan menerapkan scientific approach yang meliputi mengamati, menanya, menalar, mencoba, membentuk jejaring pada kegiatan outdoor learning. Peserta didik diarahkan untuk aktif mengamati, bertanya, memikirkan, bereksperimen atau mencoba, sampai dengan menyampaikan dan mengomunikasikan. Hasil penelitian menunjukkan bahwa implementasi scientific approach pada outdoor learning dapat meningkatkan motivasi belajar mahasiswa. Motivasi belajar mahasiswa mengalami kenaikan sebesar 5,08\% dari prasiklus sampai dengan siklus 2 dengan kategori kualifikasi motivasi tinggi. Motivasi belajar pada prasiklus sebesar 72,65\%, pada siklus 1 sebesar $73,57 \%$ dan pada siklus 2 sebesar 77,73\%.
\end{abstract}

Kata kunci: scientific approach, outdoor learning, motivasi, penelitian tindakan kelas

Abstract. This study aims to find out that the implementation of the scientific approach to the outdoor learning courses in Environmental Science can increase learning motivation of students in the academic year 2014/2015.

This research is a classroom action research which has two cycles. Each cycle consists of action planning, execution and observation, and reflection. Implementation of the actions carried out by applying a scientific approach that includes observing, asking, reasoning, trying, forming networks in outdoor learning activities. Students are directed to actively observing, questioning, thinking, experimenting, up to convey and communicate. The results showed that the implementation of the scientific approach to the outdoor learning can increase student motivation to learn. The motivation of student learning has increased by $5.08 \%$ from pre-cycle to the second cycles with high motivation qualification category. Learning motivation is $72.65 \%, 73.57 \%$ and $77.73 \%$ for pre-cycle, the first cycle, and the second cycle, respectively.

Keywords: scientific approach, outdoor learning, motivation, class action research

\section{PENDAHULUAN}

Pembelajaran efektif ditandai oleh sifatnya yang menekankan pada pemberdayaan siswa secara aktif. Pembelajaran bukan sekedar penekanan pada penguasaan pengetahuan tentang apa yang diajarkan, tetapi lebih kepada penghayatan, sehingga pengetahuan tertanam dan berfungsi sebagai muatan nurani yang dipraktekkan dalam kehidupan seharihari. Pembelajaran yang efektif menekankan bagaimana siswa mampu belajar cara belajar.

Hasil observasi proses pembelajaran di kelas menunjukkan ada permasahan di kelas. Permasalahan tersebut mengerucut pada satu masalah yaitu minimnya motivasi mahasiswa dalam mengikuti pembelajaran di kelas. Karena fungsi guru bukan hanya sekedar penyampai materi namun sekaligus sebagai pengatur bagaimana proses pembelajaran dapat berjalan efektif maka guru harus dapat membuat pembelajaran menjadi lebih menarik.

Pemerintah melalui sosialisasi kurikulum 2013 merujuk kepada salah satu pendekatan pembelajaran yang harus digunakan dalam implementasi kurikulum 2013, yaitu pendekatan scientific (scientific approach). Berdasarkan Peraturan Pemerintah Nomor 32 Tahun 2013 Pasal 19 ayat 1 menyebutkan bahwa proses pembelajaran pada satuan pendidikan diselenggarakan secara interaktif, inspiratif, menyenangkan, menantang, memotivasi peserta didik untuk berpartisipasi aktif, serta memberikan ruang yang cukup bagi prakarsa, kreativitas, dan kemandirian sesuai dengan bakat, minat, dan perkembangan fisik serta psikologis peserta didik.

$$
\text { Proses pembelajaran yang }
$$
mengimplementasikan scientific approach akan menyentuh tiga ranah, yaitu: sikap (afektif), pengetahuan (kognitif), dan keterampilan (psikomotor). Dengan proses pembelajaran yang demikian maka diharapkan hasil belajar melahirkan peserta didik yang produktif, kreatif, inovatif, dan afektif melalui penguatan sikap, keterampilan, dan pengetahuan yang terintegrasi. Ada beberapa langkah yang harus dilakukan dalam implementasi scientific approach yaitu mengamati, menanya, menalar, mencoba, membentuk jejaring. Peserta didik diarahkan untuk aktif mengamati, bertanya, memikirkan, bereksperimen atau mencoba, sampai pada akhirnya menyampaikan dan mengomunikasikan apa yang telah dipelajarinya kepada guru dan temantemannya.

Proses pembelajaran perlu menekankan pada pemberian pengalaman langsung untuk mengembangkan kompetensi agar menjelajahi dan 
memahami alam sekitar secara ilmiah [7]. Pembelajaran dapat dilaksanakan dengan model outdoor learning, dimana pembelajaran dilakukan tidak hanya di dalam kelas. Guru perlu merencanakan dan mengorganisasikan pembelajaran dengan menggunakan outdoor classroom activity secara baik agar hasil pembelajaran dapat optimal [10].

Langkah-langkah untuk mempersiapkan pembelajaran dengan outdoor learning adalah sebagai berikut[3] a)Guru merumuskan pengalaman belajar dengan teliti, b)Menentukan bentuk kegiatan yang akan dipakai, c)menyajikan pengalaman yang bersifat menantang dan memotivasi, d)Menentukan waktu pelaksanakan kegiatan, e)Menentukan rute perjalanan outdoor learning, f)Siswa dapat bekerja secara individual dan dapat bekerja dalam kelompokkelompok kecil, g)Para siswa secara aktif berperan serta dalam pembentukan pengalaman

Keuntungan metode ini [4] antara lain: (a)Kegiatan belajar lebih menarik dan tidak membosankan sehingga motivasi belajar siswa akan lebih tinggi, (b)Hakekat belajar akan lebih bermakna sebab siswa dihadapkan dengan situasi dan keadaan yang sebenarnya atau bersifat alami, (c)Bahan-bahan yang dapat dipelajari lebih kaya serta lebih factual (d)Kegiatan belajar siswa lebih komprehensif dan lebih aktif, dapat dilakukan dengan berbagai cara seperti mengamati, bertanya atau wawancara, membuktikan atau mendemonsrrasikan, menguji fakta, dan lain-lain, (e)Sumber belajar lebih kaya (f)Siswa dapat memahami dan menghayati aspek-aspek kehidupan yang ada di lingkungannya, sehingga dapat membentuk pribadi yang tidak asing dengan kehidupan membentuk sekitarnya, serta dapat memupuk cinta lingkungan.

Seperti halnya proses belajar umumnya jika seseorang tidak memiliki motivasi yang kuat dalam belajar, maka mustahil mereka akan mampu mempelajari dengan baik. Motivasi belajar merupakan suatu usaha berdasarkan pengalaman yang diperoleh, sehingga terjadi perubahan perilaku (afektif, kognitif, dan psikomotor) yang mendorong seseorang untuk bersaing dengan standar keunggulan ilmu, di mana standar keunggulan ilmu ini dapat berupa penilaian[8]. Fungsi motivasi menurut Sardiman[5] adalah (a) mendorong manusia untuk berbuat, (b) menentukan arah perbuatan ke arah tujuan yang hendak dicapai, (c) menyeleksi perbuatan-perbuatan apa saja yang dikerjakan yang serassi guna mencapai tujuan dengan menyisihkan perbuatan-perbuatan yang tidak bermanfaat. Jadi seseorang peserta didik yang mempunyai motivasi belajar tinggi diharapkan memperoleh prestasi yang lebih tinggi jika dibandingkan dengan peserta didik yang motivasinya lebih rendah.

\section{METODE PENELITIAN}

Subyek penelitian ini adalah mahasiswa Program Studi Pendidikan IPA Semester 2 T.A. 2014/2015 dan obyek penelitian ini adalah motivasi belajar. Jenis penelitian adalah Penelitian Tindakan Kelas. Desain penelitian[1] terdiri dari siklus yang dibagi menjadi empat tahapan, yaitu (a) perencanaan, (b) pelaksanaan, (c) observasi dan (d) refleksi. Siklus diulang sampai dengan terselesaikannya masalah.

Instrumen penelitian yang digunakan adalah lembar observasi dan angket. Digunakan angket sebanyak 40 soal berbentuk pilihan ganda dengan empat opsi pilihan. Uji validitas konstruk angket dilakukan dengan pengujian Konstruk (Construct Validity) melalui pendapat para ahli (judgement experts). Untuk menguji validitas isi digunakan teknik korelasi Product Moment. Apabila nilai r hitung $\geq \mathrm{r}$ tabel pada taraf signifikansi $5 \%$ maka butir soal dapat dikatakan valid. Sedangkan uji reliabilitas dihitung menggunakan rumus Alpha Cronbach, apabila nilai $\mathrm{r}$ hitung $\geq \mathrm{r}$ tabel pada taraf signifikansi $5 \%$ maka butir soal dapat dikatakan reliabel.

Siklus berulang sampai terselesaikannya masalah kelas. Penelitian ini dikatakan berhasil apabila memenuhi indikator berikut (1)Terlaksananya implementasi scientific approach pada outdoor learning, (2)Persentase motivasi mahasiswa tiap aspek mencapai nilai minimal $75 \%$ dengan kategori kualifikasi tinggi, (3)Ada peningkatan motivasi siswa dalam mengikuti pembelajaran minimal $5 \%$

\section{HASIL DAN PEMBAHASAN}

\section{A. Prasiklus}

Berdasarkan isian angket diketahui bahwa persentase motivasi mahasiswa berada pada kisaran $62,95 \%$ sampai dengan $83,48 \%$ dengan dengan kategori kualifikasi cukup sampai dengan sangat tinggi. Persentase tertinggi diraih oleh komponen situasi dan kondisi dimana mahasiswa memiliki semangat yang tinggi untuk meraih prestasi hasil belajar. Mahasiswa belum begitu menyukai hal-hal yang bersifat inovatif. Mahasiswa juga belum memiliki sikap kemandirian yang tinggi. Rata-rata motivasi mahsiswa sebesar $72,65 \%$ dan belum mencapai nilai $75 \%$. Hal ini medasari penelitian ke arah siklus 1 .

\section{B. Siklus 1}

1) Perencanaan

Rencana tindakan yang akan dilakukan antara lain: a) Pemberian materi perkuliahan sebagai bekal pelaksanaan outdoor learning; b) Memberikan penjelasan tentang implementasi scientific approach dalam outdoor learning; c) Memberikan penjelasan tentang perihal apa saja yang harus diperoleh dari outdoor learning di lingkungan; d) Mengumumkan nama-nama anggota kelompok serta e) Memberikan angket motivasi setelah pelaksanaan outdoor learning siklus 1. Selama penelitian, peneliti dibantu oleh kolaborator. Kolaborator akan mengisi lembar 
observasi aktivitas dosen dan lembar observasi aktivitas mahasiswa. Hasil observasi peneliti dan kolaborator akan dijadikan refleksi sebagai dasar untuk menentukan langkah berikutnya.

\section{2) Pelaksanaan Tindakan dan Hasil Observasi} Aktivitas

Pelaksanaan kegiatan diawali dengan pemberian materi kemudian menyampaikan indikator yang harus dicapai mahasiswa serta memberikan penjelasan mengenai scientific approach, yaitu dimulai dari mengamati, bertanya, memikirkan, bereksperimen atau mencoba, sampai pada akhirnya menyampaikan dan mengomunikasikan apa yang telah diperoleh dengan cara mempresentasikan ke depan kelas.. Pemberian materi berlangsung selama dua kali pertemuan. Pertemuan ketiga yaitu pelaksananaan outdor learning.

Hasil pengamatan menyebutkan bahwa beberapa mahasiswa mengimplementasikan scientific approach. Mahasiswa mulai mengamati kondisi lingkungan, lalu saling bertanya pada anggota kelompoknya tentang kondisi lingkungan di hadapannya. Mahasiswa tampak berfikir kemudian mencoba menjawab pertanyaan dari anggota kelompok. Jawaban-jawaban yang beragam tersebut dicatat oleh mahasiswa sebagai modal untuk mempresentasikan hasil kerja kelompok ke depan kelas.

Pertemuan keempat diisi dengan mengkomunikasikan hasil pekerjaan kelompok yang telah didapat pada pertemuan ketiga. Masing-masing kelompok maju ke depan untuk mempresentasikan hasilnya. Ketika presentasi berlangsung, kelompok lain bertanya. Pada saat presentasi terlihat beberapa mahasiswa masih mendominasi di kelompoknya. Di akhir pertemuan, peneliti membagikan angket motivasi.

Motivasi mahasiswa siklus 1 diperoleh dari isian angket. Berdasarkan isian angket, diketahui bahwa persentase motivasi mahasiswa berada pada kisaran 67,86 \% dengan kategori kualifikasi tinggi, sampai dengan 84,26\% dengan kategori kualifikasi sangat tinggi. Rata-rata motivasi mahsiswa sebesar $73,57 \%$.

\section{3) Refleksi}

Berdasarkan lembar observasi kolaborator dan peneliti, menyebutkan bahwa implementasi scientific approach pada outdoor learning telah terlaksana. Ada peningkatan motivasi sebesar $0.92 \%$ dari $72,65 \%$ pada prasiklus menjadi $73,57 \%$ pada siklus 1. Peningkatan ini belum menunjukkan ketercapaian indikator keberhasilan yaitu peningkatan aspek motivasi sebesar $5 \%$ dan ketercapaian motivasi sebesar $75 \%$ meskipun telah tercapai kategori kualifikasi motivasi yang tinggi.

Penelitian tindakan kelas siklus 2 perlu dilakukan sebagai tindak lanjut dari siklus 1. Beberapa kondisi yang perlu diperbaiki dalam siklus 1 antara lain: a) Ada mahasiswa yang tidak memperhatikan materi pembelajaran; b) Kerjasama dan tanggung jawab antar anggota kelompok belum maksimal; c) Keaktifan hanya terlihat pada beberapa mahasiswa saja; d) Beberapa mahasiswa masih mendominasi dalam kelompok; e) Ada mahasiswa yang tidak bersemangat dalam memecahkan masalah dalam materi pembelajaran; f) Mahasiswa belum termotivasi dalam belajar

Berdasarkan kekurangan dan permasalahan pada siklus I, beberapa kondisi di atas dicoba diatasi dengan: a) Peneliti lebih memotivasi mahasiswa dalam pembelajaran; b) Mahasiswa diajak berfikir kritis dengan menampilkan contoh permasalahan yang perlu dipecahkan bersama ketika pemberian materi di kelas; c) Mahasiswa diberi rambu-rambu dalam pengumpulan data di lapangan; d) Mahasiswa diberi target yang harus dicapai ketika melakukan outdoor learning, salah satunya adalah mahasiswa harus mampu memberikan solusi untuk lingkungan yang tengah dihadapinya.

\section{Siklus 2}

\section{1) Perencanaan}

Tahapan perencanaan pada penelitian tidakan kelas siklus 2 meliputi persiapan materi kuliah, persiapan contoh permasalahan lingkungan yang akan didiskusikan di kelas serta menjelaskan kepada mahasiswa perihal apa saja yang perlu diperhatikan ketika mengumpulkan data di lapangan. Peneliti juga mempersiapkan lembar angket motivasi untuk mahasiswa yang akan diisi ketika mahasiswa selesai melaksanakan outdoor learning.

2) Pelaksanaan Tindakan dan Hasil Observasi Aktivitas

Pelaksanaan kegiatan pembelajaran outdoor learning dengan implementasi scientific approach siklus 2 diawali dengan pemberian materi disertai penyampaian indikator yang harus dicapai mahasiswa. Pemberian materi berlangsung dilaksanakan pada pertemuan pertama. Pertemuan kedua yaitu pelaksananaan outdoor learning. Berdasarkan hasil pengamatan peneliti dan kolaborator di lapangan, mahasiswa telah dapat mengimplementasikan scientific approach. Kelompok-kelompok mahasiswa terlihat lebih kompak, kooperatif dan efektif. Ada pembagian tugas dalam kelompok.

Pertemuan ketiga adalah mengomunikasikan hasil pekerjaan mereka. Tiap-tiap kelompok maju ke depan kelas untuk mempresentasikan hasil pekerjaan mereka. Kelompok yang lain menanggapi dan memberi saran. Mahasiswa sangat antusias dalam mengomunikasikan hasil pekerjaan mereka maupun memberi tanggapan dan saran kepada kelompok lain. Kegiatan ini berlangsung dalam dua kali pertemuan. Peneliti membagikan angket motivasi pada pertemuankeempat. 
Tabel 1. Persentase Motivasi Mahasiswa

\begin{tabular}{|c|c|c|c|c|c|}
\hline KOMPONEN & $\begin{array}{l}\text { ASPEK } \\
\text { DASAR }\end{array}$ & INDIKATOR & $\begin{array}{c}\text { PRA } \\
\text { SIKLUS }\end{array}$ & $\begin{array}{c}\text { SIKLUS } \\
1\end{array}$ & SIKLUS 2 \\
\hline \multirow[t]{2}{*}{$\begin{array}{l}\text { A. Ciri khas } \\
\text { pribadi }\end{array}$} & $\begin{array}{l}\text { 1. Suka hal- } \\
\text { hal yang } \\
\text { inovatif. }\end{array}$ & $\begin{array}{l}\text { A. Senang membaca buku- } \\
\text { buku untuk mendapatkan } \\
\text { pengetahuan baru. } \\
\text { B. Senang bereksperimen } \\
\text { untuk mendapatkan } \\
\text { tambahan pengetahuan. }\end{array}$ & $\begin{array}{l}69,98 \% \\
\text { (tinggi) }\end{array}$ & $\begin{array}{l}71,65 \% \\
\text { (tinggi) }\end{array}$ & $\begin{array}{l}76,45 \% \\
\text { (tinggi) }\end{array}$ \\
\hline & $\begin{array}{l}\text { 2. Suka } \\
\text { bekerja } \\
\text { keras. }\end{array}$ & $\begin{array}{l}\text { A. Belajar secara terjadwal. } \\
\text { B. Tidak mudah putus asa. } \\
\text { C. Berusaha mendapatkan } \\
\text { hal-hal yang baru. }\end{array}$ & $\begin{array}{l}75,12 \% \\
\text { (tinggi) }\end{array}$ & $\begin{array}{l}75,96 \% \\
\text { (tinggi) }\end{array}$ & $\begin{array}{l}78,12 \% \\
\text { (tinggi) }\end{array}$ \\
\hline \multirow[t]{2}{*}{$\begin{array}{l}\text { B. Situasi dan } \\
\text { kondisi. }\end{array}$} & $\begin{array}{l}\text { 1. Berusaha } \\
\text { mandiri }\end{array}$ & $\begin{array}{l}\text { A. Tidak suka } \\
\text { menggantungkan orang } \\
\text { lain. } \\
\text { B. Mudah mengantisipasi } \\
\text { lingkungan. }\end{array}$ & $\begin{array}{l}68,53 \% \\
\text { (tinggi) }\end{array}$ & $\begin{array}{l}69,64 \% \\
\text { (tinggi) }\end{array}$ & $\begin{array}{l}75,67 \% \\
\text { (tinggi) }\end{array}$ \\
\hline & $\begin{array}{ll}\text { 2. } & \text { Penuh } \\
\text { semangat }\end{array}$ & $\begin{array}{l}\text { A. Berusaha agar tidak } \\
\text { gagal. } \\
\text { B. Keinginan untuk berhasil. }\end{array}$ & $\begin{array}{l}83,48 \% \\
\text { (sangat } \\
\text { tinggi) }\end{array}$ & $\begin{array}{l}84,26 \% \\
\text { (sangat } \\
\text { tinggi) }\end{array}$ & $\begin{array}{l}84,26 \% \\
\text { (sangat } \\
\text { tinggi) }\end{array}$ \\
\hline \multirow{2}{*}{$\begin{array}{l}\text { C. Semangat } \\
\text { untuk } \\
\text { berkompe- } \\
\text { tensi. }\end{array}$} & $\begin{array}{l}\text { 1. Mengatasi } \\
\text { hambatan }\end{array}$ & $\begin{array}{l}\text { A. Menyelesaikan tugas } \\
\text { dengan sebaik-baiknya }\end{array}$ & $\begin{array}{l}67,19 \% \\
\text { (tinggi) }\end{array}$ & $\begin{array}{l}67,86 \% \\
\text { (tinggi) }\end{array}$ & $\begin{array}{l}75,45 \% \\
\text { (tinggi) }\end{array}$ \\
\hline & $\begin{array}{l}\text { 2. Kemampua } \\
\text { n untuk } \\
\text { berkompete } \\
\text { nsi. }\end{array}$ & $\begin{array}{l}\text { B. Senang memecahkan } \\
\text { masalah yang dihadapi. } \\
\text { C. Memanfaatkan } \\
\text { kesempatan untuk } \\
\text { keberhasilan. } \\
\text { D. Kejelian menangkap } \\
\text { peluang yang ada. }\end{array}$ & $\begin{array}{l}71,50 \% \\
\text { (tinggi) }\end{array}$ & $\begin{array}{l}72,02 \% \\
\text { (tinggi) }\end{array}$ & $\begin{array}{l}76,41 \% \\
\text { (tinggi) }\end{array}$ \\
\hline \multicolumn{3}{|c|}{ Rata-Rata Motivasi dan Kualifikasinya } & $\begin{array}{l}72,65 \% \\
\text { (tinggi) }\end{array}$ & $\begin{array}{l}73,57 \% \\
\text { (tinggi) }\end{array}$ & $\begin{array}{l}77,73 \% \\
\text { (tinggi) }\end{array}$ \\
\hline
\end{tabular}

\section{3) Refleksi}

Peneliti bersama kolaborator melakukan refleksi terhadap pelaksanaan siklus 2. Data yang dianalisis meliputi data pada lembar observasi aktifitas dosen, data pada lembar observasi aktifitas mahasiswa, dan hasil angket. Data yang diambil berupa data kualitatif maupun data kuantitatif. Berdasarkan lembar observasi kolaborator dan peneliti menyebutkan bahwa implementasi scientific approach pada outdoor learning telah terlaksana. Penggunaan scientific approach yang diimplementasikan pada outdoor learning terbukti dapat meningkatkan motivasi mahasiswa. Ada kenaikan motivasi lebih dari $5 \%$ yaitu sebesar $5,08 \%$. Tiap-tiap aspek motivasi mampu mencapai target nilai minimal $75 \%$ dengan kategori kualifikasi tinggi. Rata-rata aspek motivasi siklus 2 mencapai nilai $77,73 \%$ dengan kualifikasi tinggi. Indikator keberhasilan penelitian dapat tercapai maka siklus bisa dihentikan

Penelitian tindakan kelas telah dilaksanakan untuk memperbaiki kondisi kelas. Pembelajaran outdoor learning dengan pendekatan scientific mampu meningkatkan motivasi belajar mahasiswa. Senada dengan penelitian yang dilakukan oleh Sujatmika[8] dan Vasques dkk[9] dimana motivasi belajar siswa meningkat melalui pemahaman metode ilmiah. Hal ini dikarenakan siswa diberikan pengalaman langsung sehingga pelajaran dirasa lebih menarik dan siswa lebih termotivasi untuk belajar.

\section{KESIMPULAN DAN SARAN}

Penelitian ini berhasil mengimplementasikan scientific approach pada outdoor learning dengan hasil berupa peningkatan motivasi berprestasi mahasiswa yang tergolong dalam kualifikasi tinggi. Pembelajaran sesekali perlu untuk dilakukan di luar kelas agar siswa mendapatkan suasana baru dalam belajar. Outdoor learning membantu guru mengaktifkan atmosfer kelas karena banyak hal menarik untuk diamati.

\section{DAFTAR PUSTAKA}

[1] Arikunto, Suharsimi, dkk. (2007). Penelitian Tindakan Kelas. Jakarta: Bumi Aksara

[2] Dinas Pendidikan Tinggi. (2013). "Data Sosialisasi Kurikulum 2013". 
[3] Hamalik, Oemar. (2001). Proses Belajar Mengajar. Bandung: Bumi Aksara

[4] Husamah. (2013). Pembelajaran Luar Kelas Outdoor Learning. Jakarta: Prestasi Pustakaraya

[5]Majid, Abdul. (2013). Strategi Pembelajaran. Bandung: Remaja Rosdakarya

[6] Peraturan Pemerintah Nomor 32 Tahun 2013 Pasal 19 ayat 1 tentang Perubahan Atas Peraturan Pemerintah Nomor 19 Tahun 2005 tentang Standar Nasional Pendidikan

[7] Rachel, Ben-Ari dan Liat, Eliassy. (2014). The Differential Effects of The Learning Environment on Student Achievement Motivation: A Comparison Between Frontal and Complex Instruction Strategies. Proquest Sociology. 31. 442-459

[8] Sujatmika, Sigit. (2010). Pembelajaran Biologi dengan Metode GI dan PBL Ditinjau dari Pemahaman Metode Ilmiah dan Motivasi Berprestasi (Studi Kasus di SMP 2 Wonosari pada Pokok Bahasan Saling Ketergantungan dalam Ekosistem Kelas VII Semester II Tahun Ajaran 2009/2010. (Tesis). Surakarta: Program Pascasarjana Universitas Sebelas Maret

[9] Vasquez, Anne V., dkk. (2012). Writing-toTeach: A New Pedagodical Approach to Elicit Exxplanative Writing from Undergraduate Chemistry Students. Journal of Chemical Education. 89. 1025-1031

[10] Wijayanti, Astuti dan Widowati, Asri. (2011). Optimalisasi Pemanfaatan Lingkungan Melalui Outdoor Classroom Activity dalam Pebelajaran Sains. Prosiding Semnas Dies Natalis ke-56. Yogyakarta. 15 Oktober 2011 